Int. J. Odontostomat., 7(2):203-206, 2013.

\title{
Odontoameloblastoma: A Diagnostic Dilemma for Maxillofacial Radiologist
}

\author{
Odontoameloblastoma: Un Dilema Diagnóstico para el Radiólogo Maxilofacial
}

Kiran Kumar; Giju Baby George; Sheeba Padiyath \& Rupak S.

KUMAR, K.; GEORGE, G. B.; PADIYATH, S. \& RUPAK, S. Odontoameloblastoma: A diagnostic dilemma for maxillofacial radiologist. Int. J. Odontostomat., 7(2):203-206, 2013.

ABSTRACT: Odontoameloblastoma is a rare neoplasm of odontogenic origin in which there is proliferation of tissue of the odontogenic apparatus in an unrestrained pattern including complete morphodifferentiation, apposition and even calcification. Till date, around 20 cases have fulfilled the histologic criteria of the current World Health Organization histologic classification of odontogenic tumors. Review of literature from 1944 to 2011 reveals only four reported cases in the anterior mandible. Here, we report a case of odontoameloblastoma in the anterior mandible in which plexiform ameloblastoma was associated with compound odontoma forming an unusual combination.

KEY WORDS: odontoameloblastoma, compound odontoma, composite odontoma.

\section{INTRODUCTION}

Odontoameloblastoma $(\mathrm{OA})$ is an extremely rare neoplasm, which is defined by World Health Organization (WHO) as: "A neoplasm that includes odontogenic ectomesenchyme in addition to odontogenic epithelium that resembles an ameloblastoma in both structure and behavior. Because of the presence of odontogenic ectomesenchyme, inductive changes take place leading to the formation of dentin and enamel in parts of the tumor" (Reichart \& Philipsen, 2004).

The term OA was included in the $1971 \mathrm{WHO}$ Histological classification of odontogenic tumors (Pindborg et al., 1971). Thompson et al., (1990) listed the various synonyms as ameloblastic odontoma, soft and calcified odontoma, adamantinoma and calcified mixed odontogenic tumor. Thoma described the first case in 1944, to date less than 50 cases of OA have been reported in the literature (Thoma \& Goldman, 1946; Mosqueda-Taylor et al., 2002).

In literature of odontoameloblastomas, only four cases in the anterior mandible were reported and all ameloblastomas were associated with composite odontoma. But in our case study, plexiform ameloblastoma was involving anterior mandible and associated with compound odontoma making an unusual combination.

\section{CASE REPORT}

A 38 year old female reported to the Department of Oral Medicine and Radiology with a chief complaint of painless swelling of one month duration in the chin region. The swelling was about $2 \times 2 \mathrm{~cm}$ when first noticed which gradually increased to the present size of $8 \times 5 \mathrm{~cm}$ with no history of paresthesia or pus discharge. The patient had undergone surgical intervention 20 years ago for a similar complaint in the left body of the mandible. Medical and family histories were non - contributory.

Extra oral examination showed (Fig. 1) solitary sessile round shaped swelling of size $8 \times 5 \mathrm{~cm}$ in the chin region which was crossing the midline, extending from right corner of the mouth till half of left body of the mandible with well defined borders. Skin over swelling was stretched, with no local rise in temperature and 


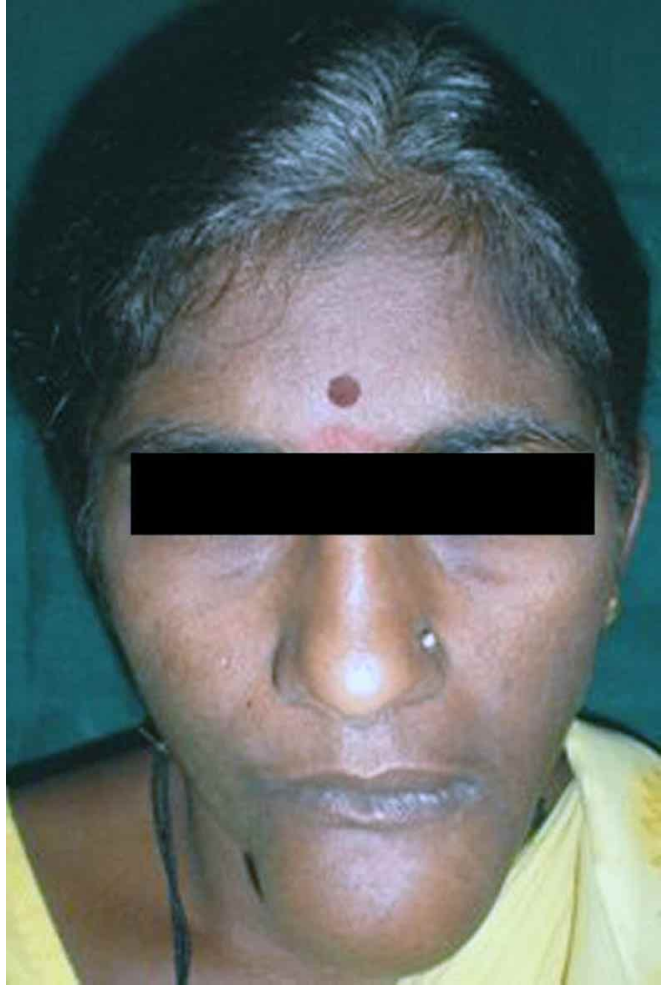

Fig.1. Clinical photograph showing extra oral swelling in the chin region.

surface changes or pulsations. On palpation, the swelling was soft, non-tender, mobile, compressible but not reducible fluctuant and non-pulsatile. Intraoral examination showed diffuse swelling in lower labial sulcus of size $8 \times 3 \mathrm{~cm}$, extending from distal aspect of 42 region till missing 36 region with obliteration of labial and left buccal vestibular sulci. The mucosa over swelling was stretched and showed surface indentations. On palpation the swelling was soft, nontender, mobile, non-pulsatile, compressible, not reducible and fluctuant. The missing teeth were $32,33,34$, $35,36,37$ and $31,41,42,43$ \& 44 were non-vital.

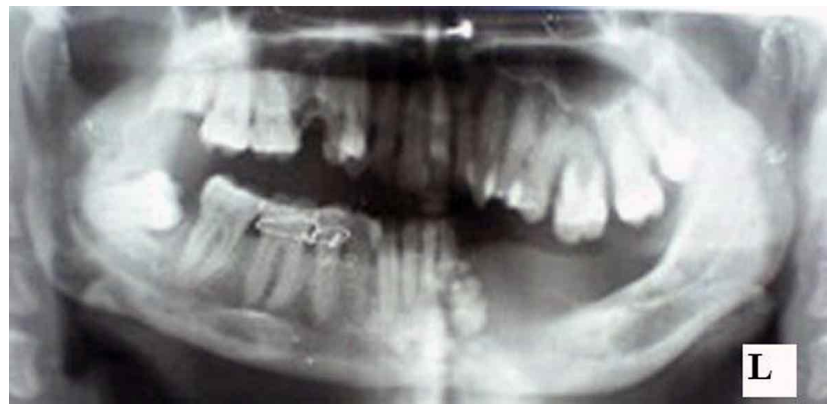

Fig. 2. OPG showing unilocular radiolucency in left body of mandible with a radiopaque mass lateral to root of 31 . mor.
On radiographic examination, orthopantomograph showed (Fig. 2) solitary unilocular radiolucency in left body of the mandible extending from symphysis region with an irregular radiopaque mass lateral to root surface of 31. Mandibular cross sectional occlusal radiograph showed findings similar to that of thopantomograph with left buccal cortical plate expansion. traoral periapical radiograph showed superiorly pushed 31 , with irregular radiopaque mass lateral to root surface and vertical alveolar bone loss.

Laboratory blood investigations were within the normal limits. On fine needle aspiration a straw colored fluid was obtained the protein content of it was 4-8 $\mathrm{gm} / \mathrm{dl}$ and cytology report fen cystic lesion. Based on clinical and radiological (icicing epithelial odontogenic tumor, and adenomatoid odontogenic tu-

Incisional biopsy specimen was taken from the missing 3233 region which revealed interconnecting strands of odontogenic epithelium (Fig. 3) with peripheral ameloblast like cells, stellate reticulum like cells between the strands and the calcified mass showed multiple pulp cavities (Fig. 4) surrounded by dentinal

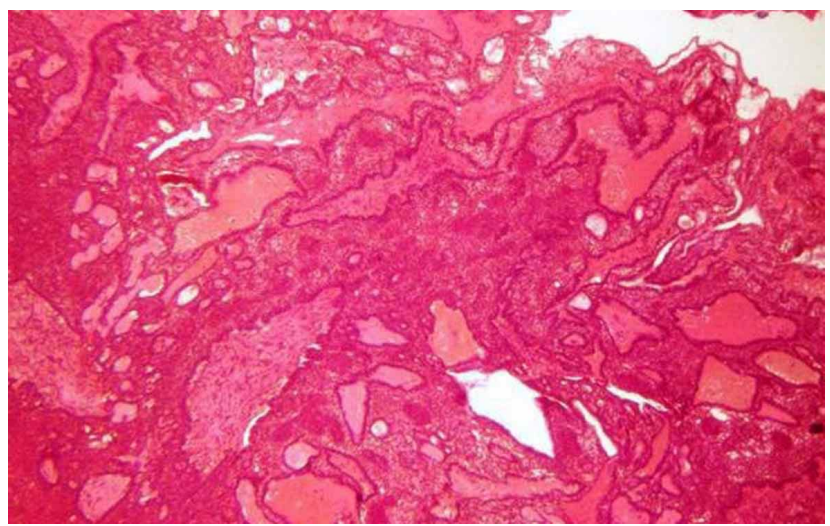

Fig. 3. H-E stained section shows long anastomosing cords and islands of odontogenic epithelium (10X magnification).

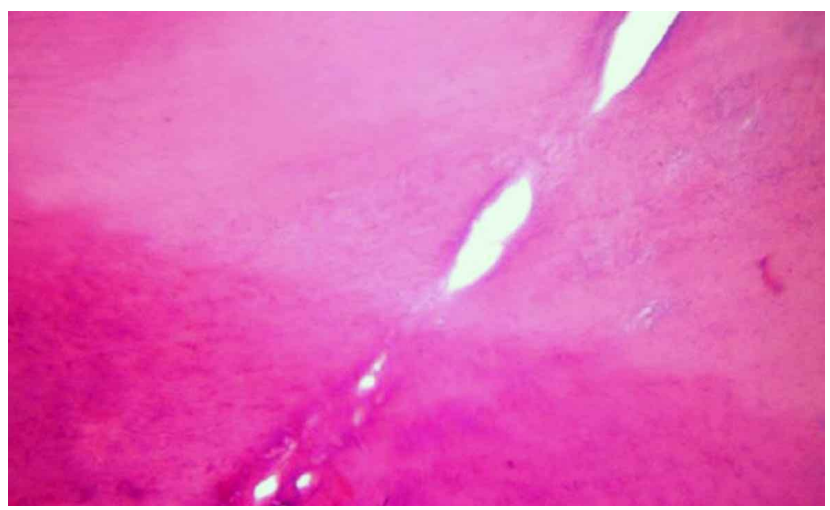

Fig. 4. H-E stained section shows multiple pulp cavities (10X magnification). 
tubules. The histopathological report was suggestive of plexiform ameloblastoma with compound odontoma. Under general anesthesia a complete enucleation of the tumor with curettage of the underlying bone was performed and there was no recurrence of tumor after three years of follow up.

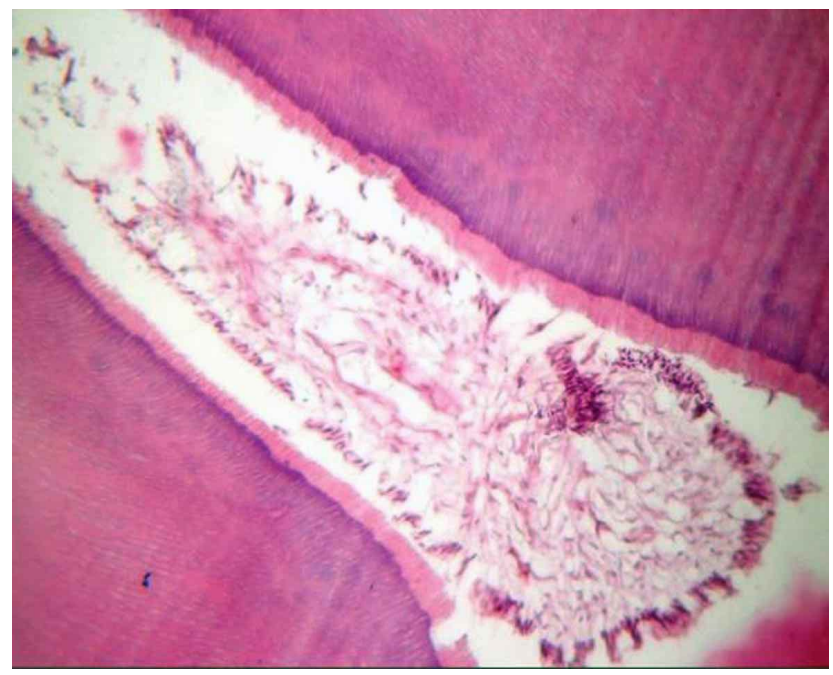

Fig. 5. H-E stained section shows pulp space with odontoblast process (40X magnification).

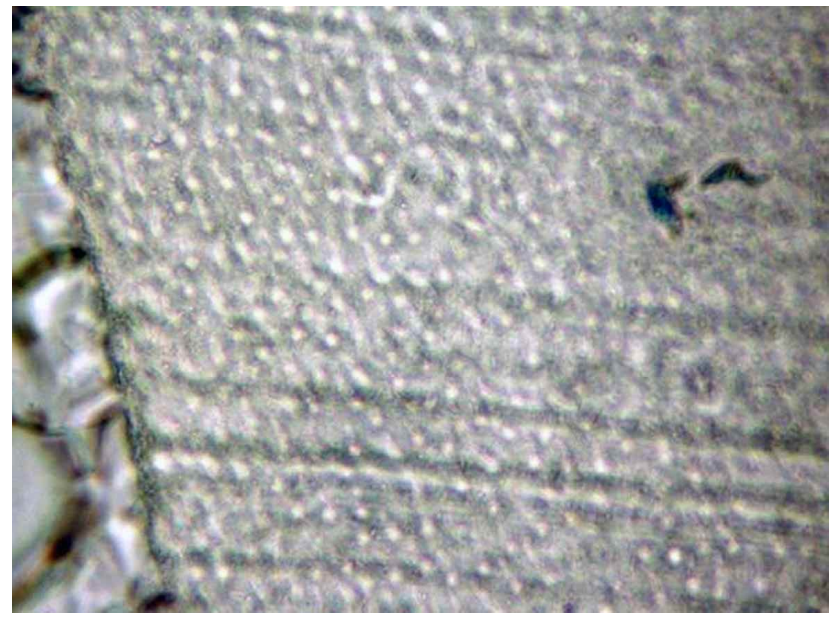

Fig. 6. H-E stained section viewed under polarized microscope shows dentinal tubules (10X magnification).

\section{DISCUSSION}

The odontoameloblastoma is an aggressive odontogenic neoplasm having incidence of $0.5 \%$ (Günhan et al., 1990). According to Mosqueda-Taylor et al., only 14 cases reported in the literature met the WHO histological and clinical criteria to be classified as OA. OA occurs between 6 months to 40 years of age predominantly in young patients with a median age of 20.12 year-old and has a predilection for males (Pindborg et al.; Mosqueda-Taylor et al.; Gupta \& Gupta, 1986; Martín-Granizo-López et al., 2004). Clinically, OA debut as a slow growing painless mass that expands the alveolus and vestibular cortex, courses with a delayed or absence of permanent teeth eruption and disturbances in occlusion. It usually occurs in the posterior segments of either jaw, with a slight inclination for the mandible with predilection for molar - premolar region and only three cases have been reported involving the anterior segment of the mandible (Gupta \& Gupta).

The pathogenesis of $\mathrm{OA}$ is unknown. According to Thompson et al., the proliferating odontogenic epithelium could induce the mesenchymal tissue to form hamartomatous mineralized dental tissue. Mosqueda-Taylor et al. proposed the coexistence of an ameloblastoma and odontoma as they would develop separately and then collide. All the evidence regarding the origin of ameloblastomas rotates around the derivatives or remnants of the dental lamina. In case of odontoameloblastoma it is only possible to speculate that the odontogenic epithelium may undergo divergent evolution partly neoplastic to all ameloblastoma and partly to undergo hamartomatous change to an odontoma (Palaskar \& Nayar, 2004).

Histopathology of OA reveals islands of odontogenic epithelium resembling an ameloblastoma, surrounded by the mesenchymal component including enamel, dentin and cementum structures in variable degrees of maturity. Additionally, dendritic cells containing melanin pigment and fine granules and coarse aggregates of melanin distributed in the epithelial cells of OA have been occasionally described, although its origin and significance is still unknown (Martín-Granizo-López et al.).

Radiographically, the lesion shows destruction of bone, expansion of cortical plates, unilocular or multilocular radiolucent area containing dense radioopacities either as solid masses or as smaller particles, which may or may not bear full resemblance to tooth form. In some instances, a single irregular radioopaque mass of calcified tissue is present which may be confused with composite odontoma. It commonly exhibits a well-defined margin, displacing the surrounding erupted teeth rather than producing root resorption (Palaskar \& Nayar).

Differential diagnosis must be made with mixed 
radiographic patterns such as developing ameloblastic fibroodontoma, calcifying epithelial odontogenic tumor, calcifying epithelial odontogenic cyst, adenomatoid odontogenic tumor, compound or complex odontomas, and cementoossifying fibroma (Mosca et al., 2009). Ameloblastic fibro-odontoma affects adult patients in a slow growing fashion, exhibits a well-defined capsule and a lack of infiltration to the surrounding bone. However, odontoameloblastoma is a locally invasive, aggressive odontogenic tumor, which spreads by infiltrating between bony trabeculae (Pindborg et al.).

Because of their rarity, controversy exists in the treatment of $\mathrm{OA}$ and the effective methods of treatment are en-bloc resection or complete resection of affected part of bone irrespective of size of the lesion. The potential for $O A$ to recur is well known due to inadequate removal (Palaskar \& Nayar). MosquedaTaylor et al., emphasized that OA should be closely followed-up for at least 5 years, because this tumor has the same biologic potential as that of an ameloblastoma (Thoma \& Goldman).

Because of the rarity of $\mathrm{OA}$ and its similarity to other odontogenic lesions, a pre-operative diagnosis is difficult to achieve based only on the clinical and radiographic features of the lesion. Nonetheless, oral radiologists and surgeons should be aware of the existence of these odontogenic tumors in order to properly treat and follow-up patients who might present them.

KUMAR, K.; GEORGE, G. B.; PADIYATH, S. \& RUPAK, S. Odontoameloblastoma: Un dilema diagnóstico para el radiólogo maxillofacial.Int. J. Odontostomat., 7(2):203-206, 2013.

RESUMEN: El odontoameloblastoma es una neoplasia rara, de origen odontogénico en el que existe proliferación tisular del aparato odontogénico en un patrón sin restricciones, incluyendo morfodiferenciación completa, aposición e incluso calcificación. Hasta la fecha, alrededor de 20 casos han cumplido todos los criterios histológicos de la actual clasificación de tumores odontogénicos de la OMS. La revisión de la literatura desde 1944 hasta el año 2011 revela sólo cuatro casos reportados en el sector mandibular anterior. Se presenta un caso de odontoameloblastoma en la region anterior mandibular donde un ameloblastoma plexiforme se asoció con un odontoma complejo formando una combinación inusual.

PALABRAS CLAVE: odontoameloblastoma, odontoma complejo, odontoma compuesto.

\section{REFERENCES}

Günhan, O.; Erseven, G.; Ruacan, S.; Celasun, B.; Aydintug, Y.; Ergun, E.; et al. Odontogenic tumours. A series of 409 cases. Aust. Dent. J., 35(6):518-22, 1990.

Gupta, D. S. \& Gupta, M. K. Odontoameloblastoma. J. Oral Maxillofac. Surg., 44(2):146-8, 1986.

Martín-Granizo-López, R.; López-García-Asenjo, J.; de-Pedro-Marina, M. \& Domínguez-Cuadrado, L. Odontoameloblastoma: a case report and a review of the literature. Med. Oral, 9(4):340-4, 2004.

Mosqueda-Taylor, A.; Carlos-Bregni, R.; Ramírez-Amador, V.; Palma-Guzmán, J. M.; Esquivel-Bonilla, D. \& Hernández-Rojase, L. A. Odontoameloblastoma. Clinicopathologic study of three cases and critical review of the literature. Oral Oncol., 38(8):800-5, 2002.

Mosca, R. C.; Marques, M. M.; Barbosa, S. C.; Marcucci, M.; Oliveira, J. X. \& Lascala, C. A. Odontoameloblastoma: report of two cases. Indian J. Dent. Res., 20(2):230-4, 2009.

Palaskar, S. \& Nayar, A. K. Peripheral odontoameloblastoma. J. Oral Maxillofac. Pathol., 8(2):104-6, 2004.
Pindborg, J. J.; Kramer, I. R. H. \& Torloni, H. Histological typing of odontogenic tumours. Jaw cysts and allied lesions. Geneva, World Health Organization, 1971. p.29.

Reichart, P. A. \& Philipsen, H. P. Odontogenic Tumors and Allied Lesions. Chicago, Quintessence Publication, 2004. pp.171-3.

Thoma, K. H. \& Goldman, H. M. Odontogenic Tumors: A Classification Based on Observations of the Epithelial, Mesenchymal, and Mixed Varieties. Am. J. Pathol., 22(3):433-71, 1946.

Thompson, I. O.; Phillips, V. M.; Ferreira, R. \& Housego, T. G. Odontoameloblastoma: a case report. Br. J. Oral Maxillofac. Surg., 28(5):347-9, 1990.

Correspondence to:

Dr. Kiran Kumar. K. R, M.D.S, Senior Lecturer

Department of Oral Medicine \& Radiology

Mar Baselios Dental College

Kothamangalam,

Ernakulam (Dist).

Kerala. PIN-686691.

INDIA

Email: krksmile@gmail.com

Received: 24-11-2012

Accepted: 16-07-2013 